(c) American Dairy Science Association, 2004.

\title{
Retinol Improves Development of Bovine Oocytes Compromised by Heat Stress During Maturation
}

\author{
J. L. Lawrence, R. R. Payton, J. D. Godkin, A. M. Saxton, \\ F. N. Schrick, and J. L. Edwards \\ Department of Animal Science, The University of Tennessee, \\ Knoxville 37996-4574
}

\begin{abstract}
The objectives of this study were to evaluate: 1 ) effects of a physiologically relevant elevated temperature on in vitro development of maturing oocytes, 2 ) effects of retinol on in vitro development of maturing oocytes, and 3) effects of retinol to improve development of oocytes compromised by an elevated temperature. Bovine oocytes were matured for $24 \mathrm{~h}$ at 38.5 or $41.0^{\circ} \mathrm{C}$ (first 12 h) in 0 or $5 \mu M$ retinol. After insemination, cleavage and blastocyst development were assessed on $\mathrm{d} 3$ and 8 , respectively. Temperature, retinol, and their interaction were included in the statistical model. Culture of oocytes at $41.0^{\circ} \mathrm{C}$ decreased the proportion of 8- to 16 cell embryos and increased that of 2-cell embryos. In addition, culture at $41.0^{\circ} \mathrm{C}$ decreased the ability of oocytes to develop to the blastocyst stage. Blastocysts derived from oocytes cultured at $41.0^{\circ} \mathrm{C}$ had fewer total nuclei. In 3 of the 7 experimental replicates, effects of $41.0^{\circ} \mathrm{C}$ to reduce blastocyst development were minimal (difference in the development of the control vs. heat stress group was $<20 \%$ ). To provide a more precise test of our hypothesis (retinol administration may improve development of oocytes compromised by heat stress), data were analyzed, including only those replicates $(\mathrm{n}=$ 4) in which heat stress reduced development to blastocyst $>20 \%$. When this was done, a significant temperature $\times$ retinol interaction was noted. The addition of retinol to the maturation medium prevented heat-induced reductions in development of oocytes to blastocyst stage. Results indicate that retinol may protect oocytes from some of the deleterious effects of heat stress.
\end{abstract}

(Key words: heat stress, reproduction, bovine oocyte maturation, retinol)

Abbreviation key: FBS = fetal bovine serum, IVF = in vitro fertilization, KSOM = potassium simplex optimized medium, NEAA = nonessential amino acids,

Received November 11, 2003.

Accepted February 24, 2004.

Corresponding author: J. L. Edwards; e-mail: jedwards@utk.edu.
$\mathbf{O M M}=$ oocyte maturation medium, $\mathbf{P Z}=$ presumptive zygotes.

\section{INTRODUCTION}

Seasonal periods of heat stress reduce milk yields and fertility in lactating dairy cows (Hansen and Aréchiga, 1999). Exposure of Holstein heifers to elevated ambient temperatures during estrus increased the proportion of retarded and degenerated embryos recovered from the uterus $7 \mathrm{~d}$ after superovulation and insemination (Putney et al., 1989). These results indicated that the oocyte is very susceptible to heat stress while preparing for fertilization. Negative effects of heat stress to decrease continued development of the oocyte are in large part due to direct effects of elevated temperatures. Edwards and Hansen $(1996,1997)$ cultured maturing bovine oocytes at $41.0^{\circ} \mathrm{C}$ and noted direct effects of elevated temperature to reduce blastocyst development. Mechanisms responsible for heat-induced reductions in the development of maturing oocytes are poorly defined. However, reduced intracellular protein synthesis (Edwards and Hansen, 1996, 1997), altered cortical granule types (Payton et al., 2003b), and increased glutathione content (Payton et al., 2003a) suggest possible alterations in the cytoskeleton and increases in free radical production.

Vitamin A and other natural retinoids have been shown to improve reproduction in heat-stressed dairy cows and the development of otherwise developmentally incompetent oocytes (Livingston et al., 2002). For example, supplementing postpartum lactating dairy cow diets with $\beta$-carotene during the summer increased pregnancy rates in the fall (Aréchiga et al., 1998). Injections of retinol palmitate (a metabolite of $\beta$-carotene) in combination with superovulation (which has been shown to reduce the developmental competence of oocytes; Merton et al., 2003) increased the mean number of quality grade 1 and 2 bovine embryos (Shaw et al., 1995). Further, administering retinol to ewes during superovulation followed by natural service increased the ability of recovered embryos to develop in vitro (Eberhardt et al., 1999). Livingston et al. (2002) reported 
that retinol administration during maturation improved the competence of otherwise developmentally challenged oocytes to develop to the blastocyst stage (development of control oocytes to blastocyst after IVF was less than 20\%). Taken together, the working hypothesis of this study was that retinol administration during maturation might improve development of oocytes compromised by heat stress. The objectives of this study were to evaluate: 1 ) effects of an elevated temperature, observed in heat-stressed dairy cows, on the development of maturing oocytes; 2) effects of retinol on the development of maturing oocytes; and 3) effects of retinol to improve development of oocytes compromised by elevated temperature.

\section{MATERIALS AND METHODS}

\section{Materials}

All reagents and chemicals used for in vitro production of bovine embryos were purchased from Sigma Chemical Co. (St. Louis, MO) unless otherwise noted. Modified Tyrode's Albumin Lactate Pyruvate (HEPESTALP, in vitro fertilization [IVF]-TALP, and SPERMTALP [Parrish et al., 1988]), and potassium simplex optimized medium (KSOM; Biggers et al., 2000) were prepared in the laboratory or purchased from Specialty Media, Inc. (Phillipsburg, NJ). Harrogate Genetics, Inc. (Harrogate, TN) donated frozen semen. Bovine ovaries, from which oocytes were obtained, were purchased from an abattoir (Gaffney, SC) between the months of March and May. Bos indicus cattle represented a small proportion $(<1 \%)$ of the females processed. Medium-199, gentamicin, penicillin-streptomycin, and nonessential amino acids (NEAA) were purchased from Specialty Media, Inc. (Phillipsburg, NJ). Fetal bovine serum (FBS) was obtained from BioWhittaker (Walkersville, MD). Follicle stimulating hormone (Folltropin-V) was obtained from Vetrepharm, Canada, Inc. (London, Ontario). Luteinizing hormone was generously provided by the USDA (Beltsville, MD). All trans-retinol was purchased from Sigma and was solubilized in ethanol (Aaper Alcohol Ethyl Alcohol USP Absolute 200 Proof) before storing at $-80^{\circ} \mathrm{C}$ as a $20 \mathrm{mM}$ stock. Concentration of each stock (range 12 to $24 \mathrm{mM}$ ) was verified using a UV-spectrometer and reading the absorbance in triplicate (wavelength $=325 \mathrm{~nm}$ ). Calculations to dilute the retinol stock to $5 \mu M$ were based on the average absorbance.

\section{In Vitro Production of Embryos}

In vitro production of embryos was performed as previously described by Edwards and Hansen (1996) with some modifications. Oocytes were harvested from an- tral follicles ranging from 3 to $8 \mathrm{~mm}$ in diameter by making checkerboard incisions approximately $2 \mathrm{~mm}$ in length and width on the ovarian surface. After evaluation, only oocytes having an evenly dark and granulated ooplasm and compact cumulus were selected for maturation. Oocytes were cultured in an oocyte maturation medium (OMM) consisting of Medium-199 containing Earle's salts, $10 \%$ FBS, $50.0 \mu \mathrm{g} / \mathrm{mL}$ gentamicin, FSH $(5.0 \mu \mathrm{g} / \mathrm{mL}), \mathrm{LH}(0.3 \mu \mathrm{g} / \mathrm{mL}), 0.2 \mathrm{~m} M$ Na pyruvate, and $2 \mathrm{~m} M$ L-glutamine for $24 \mathrm{~h}$ at $38.5^{\circ} \mathrm{C}$ in $5.5 \% \mathrm{CO}_{2}$ in humidified air. Oocytes, presumed mature, were fertilized with frozen-thawed Percoll-prepared sperm (750,000 sperm $/ \mathrm{mL}$; pool of 2 individual bulls) and cultured at $38.5^{\circ} \mathrm{C}$ in $5.5 \% \mathrm{CO}_{2}$ in humidified air. Pooled semen from the same 2 bulls was used for IVF in each experimental replicate. Approximately 13 to $17 \mathrm{~h}$ after addition of sperm, presumptive zygotes $(\mathbf{P Z})$ were denuded of cumulus and associated spermatozoa by vortexing. Presumptive zygotes were cultured in KSOM containing $0.5 \%$ BSA, $1 \times$ NEAA, penicillin $(50 \mathrm{U} / \mathrm{mL})$, and streptomycin $(50 \mu \mathrm{g} / \mathrm{mL})$ at $38.5^{\circ} \mathrm{C}$ in $5.5 \% \mathrm{CO}_{2}$, $7.0 \% \mathrm{O}_{2}$, and $87.5 \% \mathrm{~N}_{2}$ in humidified air for $8 \mathrm{~d}$ after IVF. The ability of PZ to cleave and develop to the blastocyst stage was evaluated on $d 3$ and 8 , respectively (d $0=$ day of IVF). The ability of the oocyte to cleave after IVF was assessed by recording the number of 1-, 2-, 4-, and 8- to 16-cell embryos present on $\mathrm{d} 3$ ( 70 to $75 \mathrm{~h}$ postinsemination). Blastocyst stage embryos (d 8; 187 to $195 \mathrm{~h}$ postinsemination) were stained with Hoechst $33342(5 \mu \mathrm{g} / \mathrm{mL} ; 15 \mathrm{~min})$, mounted on a glass slide (50\% glycerol), and exposed to UV light directed through a DAPI filter (excites at a wavelength of 330 to $380 \mathrm{~nm}$ ) to enumerate the total number of nuclei contained within each embryo.

\section{Developmental Competence of Bovine Oocytes Matured at an Elevated Temperature in the Presence of Retinol}

For this study, oocytes were matured at $38.5^{\circ} \mathrm{C}$ for $24 \mathrm{~h}$ or $41.0^{\circ} \mathrm{C}$ (first $12 \mathrm{~h}, 38.5^{\circ} \mathrm{C}$ thereafter) in 0 or 5 $\mu M$ retinol. Ethanol was added to the OMM at the same volume as the retinol stock to provide a diluent control $\left(0.03 \%, \mathrm{vol} / \mathrm{vol}\right.$, final concentration). Use of $41.0^{\circ} \mathrm{C}$ was appropriate, as rectal temperatures of lactating dairy cows may reach or exceed this temperature (Seath and Miller, 1946; Monty and Wolff, 1974; Ealy et al., 1993).

Variables of interest that were recorded throughout the experiment included number of $\mathrm{PZ}$ recovered after denuding oocytes of cumulus and associated spermatozoa, number of PZ that were visibly lysed after denuding, and number of PZ that cleaved and developed to blastocyst stage. Number of nuclei in resulting blasto- 
cysts also was recorded. Two independent evaluators, blind to treatments, assessed variables of interest.

To examine effects of elevated temperature in combination with retinol during maturation to activate oocytes in the absence of sperm (induce parthenogenesis), 2 additional subsets of oocytes were cultured concurrent with remaining treatments: 1 ) oocytes were matured at $38.5^{\circ} \mathrm{C}$ for $24 \mathrm{~h}$ in OMM ( $\left.\mathrm{O}=153\right)$, and 2$)$ oocytes were matured at $41.0^{\circ} \mathrm{C}$ (first $12 \mathrm{~h}$ of culture; $38.5^{\circ} \mathrm{C}$ thereafter) in combination with $5 \mu M$ retinol $(\mathrm{n}=145)$. Thereafter, oocytes were treated in a manner similar to those mentioned previously, with the exception that they were not inseminated. Development to blastocyst stage was recorded.

\section{Statistical Analyses}

Data were analyzed as a randomized block design, blocked on day of oocyte collection, using mixed models (SAS, 2001). Fixed effects of temperature, retinol, and their interaction were evaluated. The experimental unit was a group of oocytes receiving the same treatment within replicate, and block $\times$ treatment interactions were used as the correct error term. This experiment was replicated on 7 different days (a total of 323 to 345 oocytes were included in each of the 4 treatments). Data were tested for normality (Shapiro-Wilk test; $\mathrm{W} \geq 0.90$ ). Protected least significant differences were used for separating least square means.

\section{RESULTS}

The culture of oocytes at $41.0^{\circ} \mathrm{C}$ did not affect proportions of PZ recovered after removal of associated cumulus and spermatozoa (94.4 and $89.8 \%$ for 38.5 and $41.0^{\circ} \mathrm{C}$, respectively; $\mathrm{SEM}=2.2 ; P>0.15$ ) or those that had visibly lysed $\left(1.6\right.$ and $2.1 \%$ for 38.5 and $41.0^{\circ} \mathrm{C}$, respectively; SEM $=0.8 ; P>0.60$ ). In addition, the ability of oocytes to cleave after the addition of sperm was not compromised (SEM $=3.8 ; P>0.2$; Figure 1 ) when matured at $41.0^{\circ} \mathrm{C}$ during the first $12 \mathrm{~h}$ of culture. However, oocyte culture at $41.0^{\circ} \mathrm{C}$ increased proportions of 2-cell embryos (SEM $=1.3 ; P<0.04$; Figure 1), but decreased the proportion of 8- to 16-cell (SEM = 4.7; $P<0.05$; Figure 1) and blastocyst-stage embryos $(\mathrm{SEM}=2.2 ; P<0.007$; Figure 1). Moreover, blastocysts derived from heat-stressed oocytes had fewer total nuclei $(\mathrm{SEM}=6.7 ; P<0.005$; Figure 1$)$.

The addition of $5 \mu M$ retinol to the OMM did not alter the proportion of $\mathrm{PZ}$ recovered after removal of associated cumulus and spermatozoa (93.1 and 91.1\% for 0 and $5 \mu M ; \mathrm{SEM}=2.2 ; P>0.54)$ or those that had visibly lysed (1.5 and $2.2 \%$ for 0 and $5 \mu M$; $\mathrm{SEM}=0.8$; $P>0.55)$. The ability of $\mathrm{PZ}$ to cleave $(\mathrm{SEM}=3.8 ; P>$

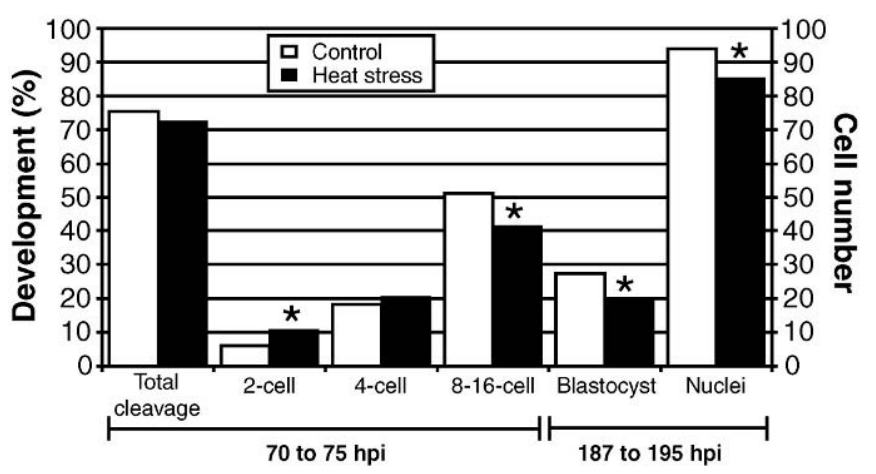

Figure 1. Development (\%) of oocytes matured at $38.5^{\circ} \mathrm{C}$ (control,

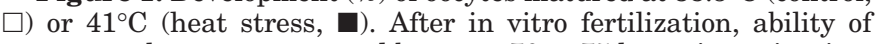
oocytes to cleave was assessed between 70 to $75 \mathrm{~h}$ postinsemination. Presence of more than one cell was indicative of cleavage, and the proportion of 2-, 4-, and 8-to-16-cell embryos was recorded. Between 187 and $195 \mathrm{~h}$ postinsemination, proportions of oocytes that developed to blastocyst were recorded. Thereafter, total number of cells was estimated in individual blastocysts by counting the number of Hoechst-stained nuclei. ${ }^{*} P<0.05$.

0.9 ; Figure 2), develop to the 8- to 16 -cell $(\mathrm{SEM}=4.7$; $P>0.6$; Figure 2) or blastocyst $(\mathrm{SEM}=2.2 ; P>0.5$; Figure 2) stages after IVF was similar for control and retinol-treated oocytes. Further, the number of nuclei was similar within blastocysts derived from oocytes cultured in retinol and the diluent control $(\mathrm{SEM}=6.7 ; P$ $>0.7$; Figure 2).

Overall there was no temperature $\times$ retinol interaction detected $(P>0.9)$. In 3 of the experimental replicates, however, effects of $41.0^{\circ} \mathrm{C}$ to reduce blastocyst development were minimal (the percent difference in the control vs. heat stress treatment was $<20 \%$ ). To have a more precise test of our hypothesis (retinol ad-

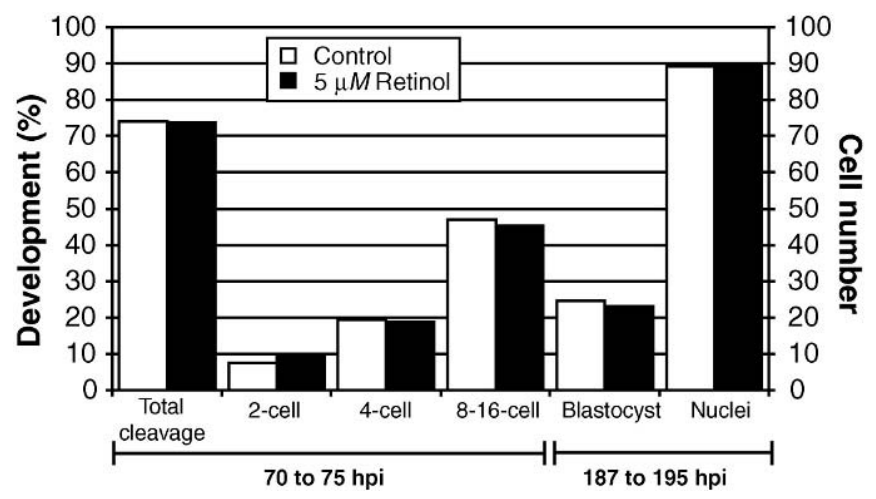

Figure 2. Development (\%) of oocytes matured in $0 \mu M$ (control, $\square$ ) or $5 \mu M$ retinol (ם). After in vitro fertilization, the ability of oocytes to cleave was assessed between 70 to $75 \mathrm{~h}$ postinsemination. Presence of more than one cell was indicative of cleavage, and the proportion of 2-, 4- and 8-to-16-cell embryos were recorded. Between 187 and 195 $\mathrm{h}$ postinsemination, the proportion of oocytes developing to blastocyst stage and the number of nuclei (or cell number) was recorded. 


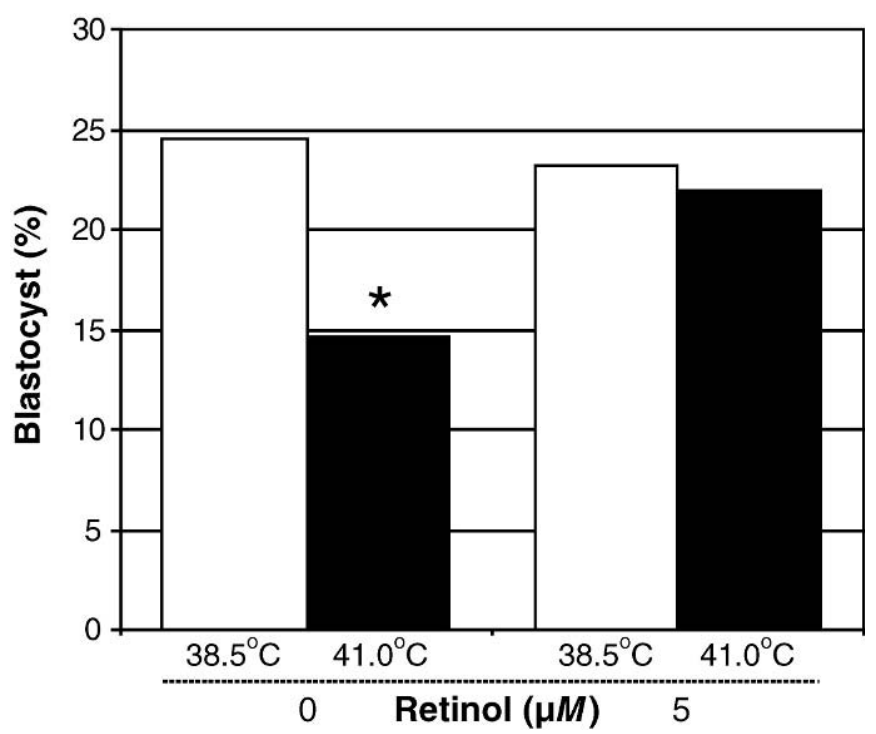

Figure 3. The proportion (\%) of oocytes developing to blastocyst stage after culture at 38.5 or $41.0^{\circ} \mathrm{C}$ without (0) or with $5 \mu M$ all trans-retinol. $*$ Temperature $\times$ retinol interaction; $* P<0.05$.

ministration during oocyte maturation may improve development of oocytes compromised by heat stress), only those experimental replicates $(n=4)$ in which percentage blastocyst difference in the control vs. heatstressed oocytes was $>20 \%$ were included in the statistical analysis. When this was done, a significant temperature $\times$ retinol interaction was noted $(\mathrm{n}=4$ replicates; 189 to 197 oocytes per treatment; $\mathrm{SEM}=2.4 ; P<0.03$; Figure 3).

Culture of oocytes at $41.0^{\circ} \mathrm{C}$ with $5 \mu M$ retinol did not increase parthenogenic activation. Blastocyst development of unfertilized oocytes cultured at $41.0^{\circ} \mathrm{C}$ with $5 \mu M$ retinol $(4.1 \pm 1.6 \%)$ was similar to those cultured at $38^{\circ} \mathrm{C}$ in $\mathrm{OMM}$ for $24 \mathrm{~h}(2.6 \pm 1.3 \%)$.

\section{DISCUSSION}

Culture of bovine oocytes at an elevated temperature observed in heat-stressed dairy cows $\left(41.0^{\circ} \mathrm{C}\right.$; Seath and Miller, 1946; Monty and Wolff, 1974; Ealy et al., 1993) disrupted further development after IVF by increasing proportions of embryos arresting at the 2-cell stage and decreasing proportions of embryos that developed to the 8- to 16-cell and blastocyst stages. Moreover, blastocyststage embryos derived from oocytes that were heatstressed during maturation had fewer total nuclei. Retinol administration during oocyte maturation ameliorated the negative effects of heat stress to reduce embryo development after fertilization.

Heat-induced reductions in oocyte development are in agreement with previous studies. Edwards and Han- sen $(1996,1997)$ showed that culture of bovine oocytes at $41.0^{\circ} \mathrm{C}$ during the first $12 \mathrm{~h}$ of maturation did not alter their ability to cleave into more than one cell, but reduced continued development to the blastocyst stage after IVF by 50 to $65 \%$. Reduced cell number in blastocysts derived from oocytes exposed to a physiologically relevant elevated temperature has been reported previously (Putney et al., 1989), documenting that heatinduced perturbations occurring in the oocyte carry over to the early embryo.

The magnitude of the effects of heat stress to reduce oocyte development varied among individual replicates (7.1 to $53.4 \%$ ), with negative effects being less prominent when the development of control oocytes was greater than usual ( $>34 \%)$. The explanation for the disparate effects of heat stress may be related to inherent differences among individual batches of oocytes related to genotype (Rocha et al., 1998), individual donors (Tamassia et al., 2003), physiological status of donor cows (Armstrong et al., 2003), subtle differences in ovary collection, shipment and oocyte evaluation, and/or other unidentified factors.

Specific mechanisms accounting for heat-induced reductions in oocyte development remain unclear. Oocytes compromised by heat stress progress to metaphase II at a rate comparable to controls (Payton et al., 2003b) but synthesize fewer intracellular proteins (Edwards and Hansen, 1996, 1997), have increased glutathione content (Payton et al., 2003a), and undergo cytoplasmic maturation faster than controls (cortical granule translocation to oolemma; Payton et al., 2003b), suggesting possible alterations in the cytoskeleton as well as increased free radical production.

Heat-induced reductions in the development of oocytes were no longer evident when $5 \mu M$ retinol was added to the OMM. Beneficial effects of retinol were noted only when the effects of heat stress were pronounced enough to reduce continued development of oocytes by at least $20 \%$ of controls. Beneficial effects of adding retinol to maturation medium for increasing development of otherwise "stressed" oocytes were observed previously (i.e., when development of control oocytes was $<20 \%$; Livingston et al., 2002).

Specific mechanisms through which retinoids increased development of oocytes compromised by heat stress remain unclear. Retinoids may act as antioxidants by scavenging free radicals and preventing lipid peroxidation (Kartha and Krishnamurthy, 1977; Ciaccio et al., 1993). Ciaccio et al. (1993) showed that administration of vitamin A to rats increased concentrations of retinol and retinyl esters in cell membranes of the brain and heart, and doing so was associated with heightened resistance of membrane lipids to oxidative stress. In other cell types, retinoid binding to retinoic 
acid receptors upregulates the transcription of antioxidant genes, including superoxide dismutase (Ahlemeyer et al., 2001) and glutathione S-transferase (Lo and Ali-Osman, 1997).

Retinoid receptors are present in the cumulus oocyte complex (retinoic acid receptor and retinoid $\mathrm{X}$ receptor; Mohan et al., 2001, 2002). Additional analyses have shown that both types of nuclear receptors, as well as retinal-binding proteins, are localized predominantly within the cumulus cells surrounding the oocyte (Malayer, personal communication). Cumulus cells are transcriptionally active (Tirone et al., 1997) and project through the zona pellucida as well as the oolemma as a means of establishing an intercellular bidirectional form of communication between the oocyte and the cumulus cells (reviewed by Eppig, 1994). As such, positive effects of retinol to improve the development of oocytes compromised by heat stress may be receptor mediated. Mechanistic effects thereafter are unclear.

Determining whether heat stress induces parthenogenesis was important because Komar (1973) reported that murine oocytes exposed to extreme elevations in temperature $\left(44.0\right.$ to $\left.45.0^{\circ} \mathrm{C}\right)$ underwent parthenogenesis. Results from our study showed that oocyte culture at $41^{\circ} \mathrm{C}$ during retinol administration did not increase parthenogenesis.

\section{CONCLUSIONS}

Retinol administration during oocyte maturation may protect bovine oocytes from harmful effects of heat stress to reduce oocyte quality. Further study on the mechanisms of retinol to improve development of oocytes compromised by heat stress is warranted. Doing so could lead to the development of therapeutic strategies for dairy producers faced with problems of heat stress to decrease oocyte quality.

\section{ACKNOWLEDGMENTS}

This research was supported in part by the USDA Initiative for Future Agricultural and Food Systems Program (Improving Fertility of Heat-Stressed Dairy Cattle; Grant No. 2001-52101-11318), USDA Hatch Funds, and the State of Tennessee through the Tennessee Agricultural Experiment Station and the Department of Animal Science (Participation in the S-299 Regional Heat Stress Project), and USDA-NRI (Grant \#1999-03637). Appreciation is extended to Tracy Livingston and Mary Roberts for technical instruction to prepare the retinol stock using a spectrometer, T. J. Wilson for technical and editorial assistance, Russell Harris of Brown Packing Co., Inc. for overseeing ovary collections, Edwin Robertson and Sam Edwards (Harro- gate Genetics, Inc., Harrogate, TN) for donation of frozen semen, Melody Malone for providing unbiased evaluation of embryo development, and to the Animal Science physiology journal club for critical review of this manuscript.

\section{REFERENCES}

Ahlemeyer, B., E. Bauerbach, M. Plath, M. Steuber, C. Heers, F. Tegtmeier, and J. Krieglstein. 2001. Retinoic acid reduces apoptosis and oxidative stress by preservation of SOD protein level. Free Rad. Biol. Med. 30:1067-1077.

Aréchiga, C. F., C. R. Staples, L. R. McDowell, and P. J. Hansen. 1998. Effects of timed insemination and supplemental $\beta$-carotene on reproduction and milk yield of dairy cows under heat stress. J. Dairy Sci. 81:390-402.

Armstrong, D. G., J. G. Gong, and R. Webb. 2003. Interactions between nutrition and ovarian activity in cattle: Physiological, cellular and molecular mechanisms. Reprod. Suppl. 61:403-414.

Biggers, J. D., L. K. McGinnis, and M. Raffin. 2000. Amino acids and preimplantation development of the mouse in protein-free potassium simplex optimized medium. Biol. Reprod. 63:281-293.

Ciaccio, M., M. Valenza, L. Tesoriere, A. Bongiorno, R. Albiero, and M. A. Livrea. 1993. Vitamin A inhibits doxorubicin-induced membrane lipid peroxidation in rat tissues in vivo. Arch. Biochem. Biophys. 302:103-108.

Ealy, A. D., M. Drost, and P. J. Hansen. 1993. Developmental changes in embryonic resistance to adverse effects of maternal heat stress in cows. J. Dairy Sci. 76:2899-2905.

Eberhardt, D. M., W. A. Will, and J. D. Godkin. 1999. Retinol administration to superovulated ewes improves in vitro embryonic viability. Biol. Reprod. 60:1483-1487.

Edwards, J. L., and P. J. Hansen. 1996. Elevated temperature increases heat shock protein 70 synthesis in bovine two-cell embryos and compromises function of maturing oocytes. Biol. Reprod. 55:340-346.

Edwards, J. L., and P. J. Hansen. 1997. Differential responses of bovine oocytes and preimplantation embryos to heat shock. Mol. Reprod. Dev. 46:138-145.

Eppig, J. J. 1994. Oocyte-somatic cell communication in the ovarian follicles of mammals. Sem. Dev. Biol. 5:51-59.

Hansen, P. J., and C. F. Aréchiga. 1999. Strategies for managing reproduction in the heat-stressed dairy cow. J. Dairy Sci. 82(Suppl. 2):36-50.

Kartha, V. N. R., and S. Krishnamurthy. 1977. Antioxidant function of Vitamin A. Int. J. Vit. Nutr. Res. 47:394-401.

Komar, A. 1973. Parthenogenetic development of mouse eggs activated by heat-shock. J. Reprod. Fertil. 35:433-443.

Livingston, T. E., D. M. Eberhardt, and J. D. Godkin. 2002. The effects of retinol on bovine embryo development in vitro. Biol. Reprod. 66(Suppl. 1):104-105. (Abstr.)

Lo, H. W., and F. Ali-Osman. 1997. Genomic cloning of hGSTP1*C, an allelic human Pi class glutathione S-transferase gene variant and functional characterization of its retinoic acid response elements. J. Biol. Chem. 272:32743-32749.

Merton, J. S., A. P. W. de Roos, E. Mullaart, L. de Ruigh, L. Kaal, P. L. A. M. Vos, and S. J. Dieleman. 2003. Factors affecting oocyte quality and quantity in commercial application of embryo technologies in the cattle breeding industry. Theriogenology 59:651-674.

Mohan, M., J. R. Malayer, R. D. Geisert, and G. L. Morgan. 2001. Expression of retinol-binding protein messenger RNA and retinoic acid receptors in preattachment bovine embryos. Mol. Reprod. Dev. 60:289-296.

Mohan, M., J. R. Malayer, R. D. Geisert, and G. L. Morgan. 2002. Expression patterns of retinoid $\mathrm{X}$ receptors, retinaldehyde dehydrogenase, and peroxisome proliferator activated receptor gamma in bovine preattachment embryos. Biol. Reprod. 66:692-700. 
Monty, D. E., and L. K. Wolff. 1974. Summer heat stress and reduced fertility in Holstein-Friesian cows in Arizona. Am. J. Vet. Res. 35:1495-1500.

Parrish, J. J., J. Susko-Parrish, M. A. Winer, and N. L. First. 1988. Capacitation of bovine sperm by heparin. Biol. Reprod. 38:1171-1180.

Payton, R. R., P. Coy, R. Romar, J. L. Lawrence, and J. L. Edwards. 2003a. Heat shock increases glutathione in bovine oocytes. J. Dairy Sci. 86(Suppl. 1):3. (Abstr.)

Payton, R. R., J. L. Lawrence, A. M. Saxton, J. R. Dunlap, and J. L. Edwards. 2003b. Cortical granule types and nuclear stage of bovine oocytes after exposure to elevated temperature during maturation. Theriogenology 59:496. (Abstr.)

Putney, D. J., S. Mullins, W. W. Thatcher, M. Drost, and T. S. Gross. 1989. Embryonic development in superovulated dairy cattle exposed to elevated ambient temperatures between the onset of estrus and insemination. Anim. Reprod. Sci. 19:37-51.

Rocha, A., R. D. Randel, J. R. Broussard, J. M. Lim, R. M. Blair, J. D. Roussel, R. A. Godke, and W. Hansel. 1998. High environmental temperature and humidity decrease oocyte quality in Bos taurus but not in Bos indicus cows. Theriogenology 49:657-665.

SAS User's Guide. Statistics, Version 8 Edition. 2001. SAS Inst., Inc., Cary, NC.

Seath, D. M., and G. D. Miller. 1946. The relative importance of high temperature and high humidity as factors influencing respiration rate, body temperature, and pulse rate of dairy cows. J. Dairy Sci. 29:465-472.

Shaw, D. W., P. W. Farin, S. P. Washburn, and J. H. Britt. 1995. Effect of retinol palmitate on ovulation rate and embryo quality in superovulated cattle. Theriogenology 44:51-58.

Tamassia, M., Y. Heyman, Y. Lavergne, C. Richard, V. Gelin, J. P. Renard, and S. Chastant-Maillard. 2003. Evidence of oocyte donor cow effect over oocyte production and embryo development in vitro. Reproduction 126:629-637.

Tirone, E., C. D’Alessandris, V. C. Hascall, G. Siracusa, and A. Salustri. 1997. Hyaluronan synthesis by mouse cumulus cells is regulated by interactions between follicle-stimulating hormone (or epidermal growth factor) and a soluble oocyte factor (or transforming growth factor $\beta_{1}$ ). J. Biol. Chem. 272:4787-4794. 